\title{
Influence of sleep in mother-child pairs from the Japan Environment and Children's Study
}

\author{
Hiroshi Kadotani ${ }^{1}$ \\ Published online: 20 March 2019 \\ (c) Japanese Society of Sleep Research 2019
}

This is the first editorial in Sleep and Biological Rhythms. As the first topic, we have chosen to describe a study of a Japanese birth cohort. Beginning in 2011, the Ministry of the Environment has conducted the Japan Environment and Children's Study (JECS), a large-scale nationwide epidemiological cohort study involving 100,000 mother-child pairs living throughout Japan [1]. The JECS has published 45 reports, including two on sleep [2]. One was on sleep duration and sleep quality before and during pregnancy [3]. The report showed that the younger the pregnant women were, the more sleep difficulties they experienced; also the younger pregnant women felt more sleep-deprived despite having had enough sleep time during pregnancy. The other published study was on mothers' sleep and their infants' birth weight [4]. Findings showed no association between the amount or quality of mothers' sleep and the risk of small-for-gestational-age birth weights among their infants.

Sleep disorders such as sleep-disordered breathing, restless legs syndrome, and periodic limb movement disorders [5] are known to be prevalent during pregnancy. It is very difficult to monitor sleep with polysomnography or without center sleep testing to detect sleep-disordered breathing or periodic limb movement during sleep in large epidemiological settings.

Further sleep studies of women during pregnancy may be needed both in epidemiological and clinical settings.

\section{References}

1. Kawamoto T, Nitta H, Murata K, Toda E, Tsukamoto N, Hasegawa M, Yamagata Z, Kayama F, Kishi R, Ohya Y, Saito H, Sago H, Okuyama M, Ogata T, Yokoya S, Koresawa Y, Shibata Y, Nakayama S, Michikawa T, Takeuchi A, Satoh H, Working Group of the Epidemiological Research for Children's Environmental Health. Rationale and study design of the Japan environment and children's study (JECS). BMC Public Health. 2014;14:25.

2. Ministry of the Environment Government of Japan. JECS Publications. http://www.env.go.jp/chemi/ceh/en/researcher/publicatio ns.html. Accessed 4 Mar 2019

3. Konishi M, Tomotaki A, Yamamoto-Hanada K, Mezawa H, Ayabe T, Ishitsuka K, Saito M, Saito H, Ohya Y, Japan Environment and Children's Study Group. Sleep status varies by age among Japanese women during preconception and pregnancy in a nationwide birth cohort study [the Japan Environment and Children's Study (JECS)]. Sleep Biol Rhythms. 2019. https://doi.org/10.1007/s4110 5-018-0195-1.

4. Morokuma S, Shimokawa M, Kato K, Sanefuji M, Shibata E, Tsuji M, Senju A, Kawamoto T, Kusuhara K, Japan Environment and Children's Study Group. Maternal sleep and small for gestational age infants in the Japan Environment and Children's Study: a cohort study. BMC Res Notes. 2017;10(1):394. https:// doi.org/10.1186/s13104-017-2675-9.

5. Wilson DL, Walker SP, Fung AM, O'Donoghue FJ, Barnes M, Howard ME. Periodic limb movements in sleep during pregnancy: a common but benign disorder? Sleep Biol Rhythms. 2018;16(1):11-20.

Publisher's Note Springer Nature remains neutral with regard to jurisdictional claims in published maps and institutional affiliations.
Hiroshi Kadotani

kadotani@belle.shiga-med.ac.jp

1 Department of Sleep and Behavioral Sciences, Shiga

University of Medical Science, Otsu, Japan 